\title{
VILÕES E ANTI-HERÓIS: \\ PERCEPÇÕES DE ADOLESCENTES SOBRE LIDERANÇAS POLÍTICAS
}

Denise D'Auria-Tardeli*

Lucian da Silva Barros **

RESUMO: Este artigo refere-se a um estudo de prevalência de caráter quanti-qualitativo que objetivou compreender as percepções que adolescentes têm sobre o perfil de um líder político e como representam a construção de uma identidade voltada para a formação ética. A coleta com 219 adolescentes entre 10 e 13 anos consiste em um questionário escrito e elaborado para esta pesquisa, com foco em vilões e anti-heróis da TV e do cinema. A linha teórica se concentra na área da Psicologia da Educação e os resultados mostram como os jovens internalizam seus valores a partir de modelos significativos, como projetam a sua participação social, e como constroem elementos identitários para o civismo.

PALAVRAS-CHAVE: adolescência, personagens, lideranças, identificação, civismo.

\section{VILLAINS AND ANTI-HEROES: ADOLESCENTS'PERCEPTIONS OF POLITICAL LEADERSHIP}

ABSTRACT: This article refers to a quanti-qualitative prevalence study that aimed to understand the perceptions that adolescents have about the profile of a political leader and how they represent the construction of an identity focused on ethical formation. The collection with 219 adolescents between 10 and 13 years old consists of a written questionnaire designed for this research, focusing on villains and anti-heroes from TV and cinema. The theoretical line focuses on the area of Educational Psychology and the results show how young people internalize their values from significant models, how they project their social participation and how they construct identity elements for civism.

KEYWORDS: adolescence, characters, leaderships, identification, civility.

\footnotetext{
* Professora Doutora do Programa de Pós-Graduação em Educação da Universidade Metodista de São Paulo. Pós Doutorado em Educação (USP). E-mail: denise.tardeli@metodista.br / denisetardeli@gmail.com ORCID: https://orcid.org/0000-0002-0195-9235

** Doutorando em Educação, Artes e Histórica da Cultura pela Universidade Presbiteriana Mackenzie. Mestre em educação pela USCS; Psicólogo formado pela UNISANTOS; Especialista em Ética, valores e cidadania na escola pela USP; Professor do SENAC SP. E-mail: lucian.barros@hotmail.com_ORCID: https://orcid.org/0000-0001-7592-3473
} 


\section{Introdução}

A adolescência é uma fase do desenvolvimento humano que compreende profundas mudanças de ordem biológica, psicológica e social. Perante as pressões sociais exercidas pelo meio em que vive, além das próprias crises provocadas pelas mudanças no corpo, pela emergência de diferentes sentimentos e afetos, e ainda o movimento interno de construção da identidade (ERIKSON, 1987), o adolescente deve firmar sua personalidade se construindo como um sujeito autônomo, capaz de refletir sobre o mundo e nele operar, de modo a transformá-lo.

Nesse processo de construção da identidade, o qual ocorre por toda a vida, compreende-se que certas figuras de autoridade, exercem profunda influência sobre os adolescentes. Seja no modo de agir, falar, pensar, vestir-se ou mesmo de se comportar, os adolescentes podem tender a repetir ou mesmo a se inspirar em seus ídolos, tomando-os como referência, seja em um aspecto considerado positivo ou negativo. Todavia, podemos destacar ainda que o processo de elaboração psíquica é mais complexo do que a simples repetição de comportamentos, porém é inegável que certa influência ou mesmo tendência para pensar ou agir, possa se concretizar a partir do que os adolescentes apreendam da realidade ao admirarem os seus ídolos.

Dessa forma, consideramos relevante compreender como tais figuras, representadas por ídolos ou outros personagens que compõem o universo adolescente, operam no sentido de influenciar o modo de pensar, sentir e agir dos jovens no mundo contemporâneo.

Personagens do cinema, dos quadrinhos, dos desenhos animados e das séries (de TV ou streaming) compõem esse universo de significações em que os jovens estão imersos, seja com os super-heróis, com os vilões (anti-heróis), ou com quaisquer outros personagens que exerçam uma liderança sobre os demais nos contextos onde se inserem e que podem despertar um magnetismo e provocarem o engajamento dos seus seguidores para alcançarem seus objetivos. Nenhum super-herói ou vilão se faz sozinho; este deve ser capaz de conquistar adeptos para suas causas, e para tal, faz uso de suas características de personalidade, tais como carisma, inteligência, poder de persuasão, entre outras, o que consideramos causar também um forte poder de impacto e influência no desenvolvimento da personalidade dos adolescentes.

A escolha pelo trabalho com os vilões dá-se pela constatação de que estes são personagens antagônicos, que despertam muitas vezes, sentimentos ambivalentes (amam-se e odeiam-se os vilões ao mesmo tempo), e que exercem grande fascínio nos adolescentes. É possível constatar que, ao contrário das crianças, que em geral admiram mais os super-heróis, os adolescentes têm certa admiração pelos vilões ou mesmo os anti-heróis, visto que são personagens mais complexos e que requerem maior elaboração psíquica na compreensão de suas ações. Isso nos leva a compreender que, ao admirar um vilão, o adolescente pode estar exercendo uma maior complexidade de seu raciocínio e pensamento.

Neste estudo, pareceu-nos interessante aproximar as figuras representadas pelos personagens fictícios do cinema e das séries às lideranças políticas, compreendendo que, muitas vezes, é na 
adolescência que o despertar para a participação social e política na sociedade acontece (MESQUITA et al, 2016). Assim, podemos aferir que os adolescentes percebem e se apropriam dos líderes políticos da mesma forma que se identificam com os personagens marcantes do cinema e da TV. Field (2002) relata que devemos abstrair um personagem como um "ponto de vista", por meio do qual contemplamos a realidade.

Comparando líderes e personagens fictícios, podemos avaliar que o impacto dos dois é o mesmo. Segundo McKee (2002), encontramos dois conceitos-chave para tal: primeiro, a caracterização, a qual se refere ao âmbito físico, à aparência, aos detalhes que compõem a psicologia e ao entorno das duas figuras; segundo, a personalidade, que é a forma na qual eles reagem aos estímulos de seus contextos. Ainda segundo McKee (2002),

a verdadeira personalidade somente pode se expressar através das decisões tomadas diante de dilemas. Como a pessoa escolhe atuar em uma situação de pressão definirá quem ela é, e quanto maior for a pressão, mais verdadeira e profunda será a decisão tomada pelo personagem (p. 447). ${ }^{1}$

A esses conceitos se somará um novo elemento: as contradições. Uma contradição faz com que um personagem se debata entre várias opções, e a ela lhes conferem uma maior profundidade a sua existência. Essas contradições são paradoxais e podem ser encontradas tanto na vida real - dos líderes políticos - quanto no plano simbólico - nos personagens fictícios -, nos contextos em que realmente se conhece a pessoa, quando ela é capaz de surpreender com um determinado comportamento que não se esperava, ainda que siga sendo, na essência, a mesma pessoa que sempre foi.

Por isso, apesar de tudo, em narrativas fictícias, os personagens para serem impactantes, devem guardar a coerência e assegurar alguns parâmetros invariáveis, como os líderes políticos em seus contextos. Toda ficção trata de imitar a realidade, e não podem se afastar disso, senão os espectadores se sentiriam decepcionados, assim como os eleitores quando votam em determinada liderança que, após assumir seu mandato, não corresponde as expectativas, causando um possível sentimento de decepção.

Sendo assim, esta pesquisa tem como objetivo central discutir o despertar do engajamento político com o foco na identidade de um líder, por meio das percepções de adolescentes a respeito dos personagens que compõem esse universo fictício, em especial os vilões/anti-heróis de filmes de cinema e séries de TV.

Um ponto crítico que a pesquisa também pretende observar diz respeito a considerar que os adolescentes precisam compreender a natureza das ações de seus governantes (lideranças políticas), refletindo sobre o que os motiva a agir de determinada forma ou de outra no exercício de seu papel público. Dessa maneira, poderemos avaliar como os adolescentes se motivam, ou não, a participarem nas transformações políticas e sociais e se atribuem importância para essas participações na esfera pública.

\footnotetext{
${ }^{1}$ Citação traduzida livremente da língua espanhola pelos autores.
} 


\section{Método}

Esta pesquisa é um estudo de prevalência, de caráter quanti-qualitativo, para verificar a incidência das respostas dos 219 sujeitos avaliados, na faixa etária de 10 a 13 anos, escolarizados em instituições privadas de ensino, da região da Baixada Santista do Estado de São Paulo, de ambos os sexos. A escolha das idades está na característica muito peculiar dessa etapa do desenvolvimento².

Essa faixa etária, atualmente chamada de pré-adolescência, apresenta uma moralidade de intercâmbio, segundo Piaget (1994), ou seja, o sujeito tem seus próprios interesses que podem estar em conflito com os interesses dos demais. A descoberta de que cada um tem seus próprios interesses leva o pré-adolescente a superar o absolutismo e o realismo moral da fase anterior, fazendo-o adotar uma perspectiva moral hedonista e relativista, segundo a qual, a melhor forma de resolver os conflitos é por meio de intercâmbios instrumentais diretos e concretos, tratando os interesses de cada indivíduo de forma estritamente igual.

Por isso, essa fase de transição, explicada também por Kohlberg (1984), pareceu-nos bastante interessante para avaliar o que os sujeitos percebem do cenário político mundial e nacional, e assim, realizarmos uma discussão sobre os valores relativos à liderança política e à noção de engajamento cívico, avaliando como esses pré-adolescentes concebem e se identificam com os perfis de personagens fictícios de impacto cultural. ${ }^{3}$

O questionário elaborado para a pesquisa envolveu uma única arguição sobre a justificativa da escolha de um personagem do cinema e de séries, numa lista de dez, os quais são considerados vilões, para os protagonistas das suas respectivas histórias. A escolha dos dez personagens foi selecionada com base nos vilões que mais apareceram nas mídias fílmicas dos últimos quatro anos, período considerado por estudiosos (GONZALEZ REQUENA, 2007) como pós-clássico, o que implica na valorização do espetáculo advindo da psicologia dos personagens.

O personagem é o agente que dá vida à história, seja uma pessoa, um animal ou um objeto. É a força que nos arrasta e nos converte em testemunhas de suas virtudes, seus defeitos, seus heroísmos ou suas angústias. Pérez Rufí (2008) afirma que é difícil tratar de conceitos como "personagem" e "ação" de forma dissociada, já que eles funcionam de maneira complementar.

O contexto da pós-modernidade se desprendeu totalmente da forma de relato clássico para incluir novas formas de narrativas que obtiveram êxito com o espectador. Essas narrativas se tornaram ferramentas muito mais eficazes para a promoção da desmistificação total da sociedade ocidental, e os adolescentes são os que mais absorvem tudo isso por conta da construção de suas identidades e da busca de modelos significativos. No contexto pós-moderno, os personagens de filmes de heróis e super-heróis

\footnotetext{
${ }^{2}$ A presente pesquisa foi aprovada pelo Comitê de ética e pesquisa. Número do parecer 3.423.733.

${ }^{3}$ Precisamos fazer uma observação que se refere à concepção de adolescência. Neste artigo, não sentimos a necessidade de diferenciar os termos Adolescência e Juventude. Mesmo já havendo um grande debate sobre o uso dos termos, nesse contexto trataremos os dois como sinônimos, apesar de não serem.
} 
são apresentados com uma carga afetiva e uma diversidade de emoções tão fortes que provocam imediatamente a empatia nos espectadores.

Empatia significa colocar-se no lugar do outro. No íntimo do protagonista, seja vilão ou herói, o público reconhece certa humanidade compartilhada. Obviamente, os personagens e os espectadores não são parecidos em todos seus aspectos [...]. Mas há algo no personagem que nos toca sensivelmente [...] (MCKEE, 2002, p. 178). ${ }^{4}$

Esse instrumento foi organizado especialmente para este estudo, pois a partir de personagens fictícios, acredita-se que o elemento simbólico contido nas identidades dos vilões pode proporcionar a projeção direta dos adolescentes. Além disso, os filmes são atraentes ao público jovem que se empenha em ver certos personagens reagirem como reagiria qualquer pessoa na mesma situação.

A justificativa é a de que a arte cinematográfica representa uma forma de narrativa e, como tal, depende da identificação como elemento de atração por parte do espectador. Os espectadores se deleitam vendo essa imitação de suas vidas e de seus sentimentos. Segundo Aristóteles (1997):

A imitação é natural para o homem, desde a infância, e esta é uma das suas vantagens [...], e aprende desde o início por imitação [...]. Ainda que os objetos se configurem como situações penosas de se assistir, nos deleitamos em contemplar na arte, as representações mais realistas [...] (p. 97).

O espectador se nutre com o que vê. Apesar de o objetivo ser de entretenimento, consegue de alguma maneira aprender com as emoções sentidas durante a narrativa da história. O espectador é cativado por algo que seja atraente, que possa sentir empatia, ou seja, ele se identifica com os personagens, e essa identificação faz com que o espectador se sinta partícipe da história.

Para Molano (2009), o espectador se converte em líder da representação da qual é testemunha e, junto com o relato e a psicologia dos personagens, a atenção do espectador segue na direção desejada. As dimensões psicológicas são primordiais para assumir a credibilidade de um personagem, ainda que se trate de um herói, pois, se ele não apresenta certos parâmetros obscuros, não consegue conectar o espectador que irá encontrar satisfação na abordagem do conflito interno, superando a própria narrativa da história.

Por isso, fizemos a escolha dos vilões para discutir a concepção de liderança política, já que são personagens que funcionam com o signo referencial e, portanto, remetem a uma realidade palpável para o espectador. Os personagens vilões são os que atraem mais diretamente, proporcionando um reflexo de conflitos cotidianos com que o espectador comum se identifica. Os conflitos universais são a chave, como os temas de amor, traição, vingança.

O tratamento dos dados coletados se deu evidenciando os três personagens mais selecionados para serem discutidos na análise de perfil e responder à seguinte pergunta de pesquisa: Como os adolescentes

\footnotetext{
${ }_{4}^{4}$ Tradução livre da língua espanhola feita pelos autores.
} 
percebem simbolicamente um líder politico na sociedade atual e desenvolvem a noção de liderança a partir dos personagens fictícios de filmes e séries, em especial os vilões/anti-heróis? E para essa pergunta, temos as seguintes hipóteses:

- as capacidades do pensamento adolescente, características de sua etapa do desenvolvimento, possibilitam uma compreensão mais ampla dos vilões/anti-heróis, a qual gera certa admiração;

- há uma percepção ética/não ética de liderança política que permite a identificação com valores morais (dignidade e respeito) e materiais (poder e bens) que é desencadeada a partir da mídia interativa;

- a identificação se dá pelo carisma causado pelos seus dotes sobrenaturais, faculdades mágicas, heroísmo exagerado, poder intelectual ou oral que gera uma devoção pessoal ao herói guerreiro, ou ao vilão;

- os vilões/anti-heróis representam para os adolescentes uma maneira mágica de superar suas dificuldades, pois identificam neles certo poder e potência para fazer o que quiserem, sem se importarem com as consequências, o que pode significar certo grau de imaturidade em seu desenvolvimento moral.

A seguir apresentamos os resultados da pesquisa, seguidos das discussões que tentam dar conta de abarcar os objetivos elencados.

\section{Discussão dos resultados}

Os resultados quantitativos da investigação são apresentados Quadro 1. No qual, destacamos os três personagens mais escolhidos pelos adolescentes pesquisados (Coringa, Thanos e Voldemort).

As justificativas das escolhas foram destacadas na constatação dos posicionamentos teóricos sobre o tema. Em função da grande variedade de justificativas, não foi possível categorizar esses registros; além disso, acredita-se que os comentários são mais ilustrativos quando comparados à fundamentação teórica.

Importante destacar que o próprio contexto cultural dos adolescentes pesquisados tem grande influência em suas respostas quanto aos vilões elencados por eles. Alguns personagens trazem um maior apelo midiático e difusão na cultura mundial, como é o caso do próprio Coringa, do filme "Batman - o Cavaleiro das Trevas" (2008), o qual aparece em primeiro lugar com 24,48\% das respostas. Esse personagem vem sendo, ao longo das três últimas décadas, constantemente retratado no cinema ${ }^{5}$, fazendo com que sua prevalência na cultura juvenil seja fundamentada, por ser frequentemente reafirmada. Todavia, chama-nos a atenção neste estudo as justificativas dos jovens para essa escolha - as quais analisaremos mais à frente -, comprovando a relevância desse personagem.

\footnotetext{
${ }_{5}$ Cesar Romero interpretou Coringa no filme "Batman - O Homem Morcego", em 1966, e na série de TV, "Batman", entre os anos de 1966 e 1968; Jack Nicholson deu vida ao vilão em "Batman”, de Tim Burton, de 1989; Heath Ledger atuou como Coringa em "Batman - O Cavaleiro das Trevas", de 2008, e ganhou um Oscar, mesmo depois de sua morte; Cameron Monaghan atuou como Coringa na série de TV, "Gotham”, de 2014; Jared Leto interpretou o personagem no filme "Suicide Squad” (Esquadrão Suicida), de 2016; e em 2019, Joaquim Phoenix fez o Coringa, no filme "Joker", e também ganhou o Oscar pelo papel.
} 
Quadro 1 - Porcentagem dos personagens nas citações dos adolescentes

\begin{tabular}{|l|l|}
\hline $\begin{array}{l}\text { Dos personagens relacionados abaixo, qual você acha mais interessante? } \\
\text { Justifique sua resposta: }\end{array}$ & \\
\hline Nenhum & $0,45 \%$ \\
Darth Vader (Star Wars) & $7,16 \%$ \\
Apocalipse (X-Men) & $0,91 \%$ \\
Thanos (Guardiões da Galáxia) & $\mathbf{2 3 , 1 6 \%}$ \\
Loki (Os Vingadores) & $8,14 \%$ \\
Lex Luthor (Superman) & $2,54 \%$ \\
Coringa (Batman) & $\mathbf{2 4 , 4 8 \%}$ \\
Negan (The Walking Dead) & $7,67 \%$ \\
Rumpelstiltiskin (Once Upon a Time) & $9,43 \%$ \\
Ramsey Bolton (Game of Thrones) & $0,45 \%$ \\
Voldemort (Harry Potter) & $\mathbf{1 3 , 5 1 \%}$ \\
\hline TOTAL & 219 \\
\hline
\end{tabular}

Fonte: Elaborado pelos autores, 2020.

Muito próximo, em segundo lugar, encontramos o personagem Thanos, dos filmes "Guardiões da Galáxia” (2014) e da saga “Avengers” (2012-2019), pertencente ao Universo Cinematográfico Marvel $\left(\mathrm{MCU}^{6}\right)$, o qual ganhou destaque especial a partir de 2014 nos filmes do MCU, sendo considerado um vilão mais contemporâneo. Com 23,16\% das respostas dos jovens, esse é um vilão que podemos considerar como emblemático, pois com suas ações pensa fazer o que é melhor para o universo, equilibrando a superpopulação ao eliminar metade de todas as raças. Thanos personifica o poder por ser considerado um deus e por conseguir dominar, por meio da manopla do infinito ${ }^{7}$, todas as "joias da alma".

$\mathrm{Na}$ sequência de prevalência de interesses dos adolescentes, ficando como o terceiro personagem mais citado (13,51\%), encontra-se Voldemort, da saga de filmes "Harry Potter" (2001-2011). Esse vilão, considerado o bruxo dos bruxos - "aquele que não se pode dizer o nome" -, ganhou importante destaque nas duas últimas décadas, devido aos sucessos dos livros de J. K. Rowling e dos filmes do produtor David Heyman, sendo o principal antagonista, mesmo antes de sua aparição oficial, no quinto filme da série intitulado "Harry Potter e o Cálice de Fogo" (2005), passando a ser parte constante do universo cultural infanto-juvenil.

Assim, consideramos inicialmente que esses três vilões (Coringa, Thanos e Voldemort) carregam em suas personalidades características básicas que nos auxiliam na compreensão de como as lideranças

\footnotetext{
${ }^{6}$ Marvel Cinematic Universe.

7 A Manopla do Infinito foi projetada para armazenar seis das "joias da alma”, mais conhecidas como as Joias do Infinito. Quando usadas em conjunto, seus poderes permitem ao usuário fazer qualquer coisa que deseje. Disponível em: https://marvel.fandom.com/pt-br/wiki/Manopla do Infinito_(Item). Acesso em: 20 jul. 2020.
} 
políticas podem ser percebidas pelos adolescentes, e como podem agir de modo a influenciar a própria construção de suas personalidades, sob um ponto de vista maniqueísta que influenciaria nas tomadas de decisão e na resolução de seus problemas. Nosso objetivo neste estudo não se reduz à análise da conduta do vilão/anti-herói, se o que ele faz é considerado bom ou mau, mas sim em compreender, perante os dados apresentados nas suas histórias, como os adolescentes percebem a identidade desses personagens, se eles se identificam com suas condutas e como justificam suas preferências. A seguir apresentaremos alguns pontos de discussão.

\section{As características de liderança e dos líderes}

O tema da liderança teve uma especial atenção durante a última década do século XX devido às transformações estruturais que o modelo estatal de ordem social sofreu, nos pilares da representação política, que debilitou enormemente a capacidade que tinham os partidos políticos em articular e agregar demandas sociais e formular projetos e alternativas políticas.

Avaliando que as sociedades contemporâneas não têm identidades firmes e fixas, mas ao contrário, transitórias e dependentes da encenação política, constata-se que os vínculos de representação se tornam mais personalizados do que institucionalizados, o que faz surgir um modelo de comunicação política dirigida a um público heterogêneo, com figuras representativas chamadas de líderes carismáticos, que se apresentam à sociedade dando unidade política ao corpo social e estabelecendo mecanismos eficazes de decisão coletiva (NOVARO, 2000).

Nessa direção, os novos líderes são necessários para a sobrevivência da política do momento, que se baseia na ideia da representação política como construção de um terreno em que se compõe uma vontade comum e uma autoridade legítima como mediação entre pluralidade social e unidade do Estado. A liderança pessoal, essência das instituições políticas, não surge então de uma identificação subjetiva com um líder, mas sim, da própria relação representativa (NOVARO, 2000).

E para os adolescentes deste século, que presenciam esse cenário político, constroem concepções de lideranças baseadas, muitas vezes, em representações frágeis a partir das mídias interativas que minimizam alguns dos elementos básicos de representação política, que deixa a dúvida sobre se os novos líderes são ou não nocivos para a democracia do País.

Curiosamente, vemos que os jovens no contexto atual passam a se identificar com personagens fictícios, numa elaboração imatura e fantasiosa por causa do cenário político incipiente e da falta de modelos éticos significativos. E as identificações recaem não nos personagens heroicos do cinema e da TV, mas nos personagens opostos. Uma fala inicial de um dos adolescentes pesquisados parece exemplificar isso: "eu gosto de vilões nos filmes...” (POCS, menino, 12 anos) ${ }^{8}$.

\footnotetext{
${ }^{8}$ A fim de preservar a identidade dos jovens participantes, ao longo da discussão, estes serão identificados apenas pelas iniciais, gênero e idade.
} 
Baseado nos estudos de Jiménez Gascón (2010), podemos comparar as características do vilão e do líder político a partir das funções que exercem em seus respectivos contextos:

a) função de destacar ou realçar: potencializam a imagem positiva do herói/cidadão. É uma função baseada no contraste;

b) função criadora ou geradora de situações: criam momentos em que os heróis/cidadãos devem intervir socialmente;

c) função explicativa ou justificadora: realçam a importância das mensagens e propósitos das histórias/narrativas;

d) função polarizadora: estabelecem vínculo com os espectadores/cidadãos, fazendo-os cúmplices dos seus pontos de vista. Dão uma lição moralizadora de certa forma ao público, levando a um sentimento de culpa da maldade, no caso de idealizarem o mal, e/ou denunciando ou criticando, quando não são empáticos;

e) função perpetuadora: mantêm a crença em ideais e princípios básicos que não devemos duvidar, como leis, políticas ou punição pelo crime e corrupção;

f) função catártica: projetam nos espectadores/cidadãos as fantasias amorais ou ilegais que em sua vida real não vão poder satisfazer;

g) função adversária: focalizam desconfiança ou ódio a partir de uma direção concreta, que varia em função da situação política.

Concluindo, a liderança está relacionada com o poder. O líder é uma pessoa capaz de alterar o curso dos fatos (BLONDELL, 1987). A liderança não se consegue pelo fato de ter subordinados, mas sim, pela sua legitimação por parte de seus seguidores. O líder e seus seguidores - que são indispensáveis para a liderança - se encontram em uma relação de influência recíproca, pois a liderança também é uma relação de transação, já que o líder deve distribuir algum tipo de recurso para poder influir e dirigir os atos de seus seguidores, sejam estes fiéis - aqueles que se comprometem por razões de caráter moral ou mercenários - que unicamente se comprometem por interesse próprio (ZUKIN et al., 2006).

\section{As concepções dos personagens nas falas dos adolescentes}

Como já apresentado anteriormente, o personagem Coringa foi o mais citado pelos sujeitos pesquisados. No filme de Christopher Nolan, "Batman - o Cavaleiro das Trevas" (2008), esse personagem se mostra totalmente invariável ao longo do filme, no que se refere a sua condição moral e o seu objetivo, aspecto muito valorizado no mundo jovem, já que eles próprios estão buscando seus objetivos na vida.

O Coringa, mesmo sendo uma figura secundária, serve para demonstrar o atrativo de um personagem que não varia durante a história. Ele aprenderá a partir dos acontecimentos que se sucedem, mas não mudará sua forma de ver o mundo. Uma das meninas relata que "ele é muito inteligente, cumpre seus 
deveres e e faz a própria justiça" (MEGS, 13 anos). No contexto da história é possível afirmar que não sabemos nada sobre o seu passado. E como relata um dos sujeitos - (PBS, menino, 10 anos) -, "ele é imprevisivel e isso faz. com que se queira saber o que ele vai fazer..." Simplesmente, sua presença é resultado de uma mistura de ecletismo e de entretenimento, no relato de um dos sujeitos (LANL, menino, 13 anos): "ele é muito legal, ele diverte o público, a sua risada é macabra e a pintura do rosto dele também é legal...".

Em cada cena na qual ele aparece, mostrando cinismo e sadismo, e sendo um cínico, demonstra não ser um louco qualquer, já que seus argumentos são lógicos, e se serve deles para enganar a polícia e a todos os outros. Os adolescentes trazem em suas respostas esse aspecto para justificarem suas escolhas: "ele não é um vilão comum, usa a inteligência com armadilhas e bombas contra o Batman" (EQS, menino, 11 anos); "ele é bem malandro e engraçado" (CFO, menina, 11 anos); "ele é engraçado e ao mesmo tempo ele é do mal" (IIDA, menina, 11 anos); "é muito inteligente" (JPCS, menino, 11 anos).

Seu antagonista, Batman, é um personagem com princípios também inabaláveis, mas de uma forma contrária. Esse choque de forças opostas é o que faz do filme um entretenimento vibrante. Batman segue tentando desfazer as maldades do Coringa e procurando não cair no jogo psicológico que este realiza com todos. Os adolescentes percebem esse conflito de forças, como é possível constatar em uma das falas: "ele não é só um vilão, é como se fosse o mal e o Batman não pode existir sem ele" (HELS, menino, 12 anos). Esse comentário do adolescente é muito interessante porque no filme "Batman", de Tim Burton (1989), o personagem Coringa se explica a Batman, dizendo que ele (Batman) foi o responsável pela transformação do Coringa, referindo-se ao episódio em que Batman o enfrenta. Mas é imediatamente retrucado por Batman, que afirma ser ele (Coringa) o responsável, em primeiro lugar, por Bruce Wayne ter se transformado em Batman, fazendo referência ao fato de ter presenciado a morte de seus pais pelo então ladrão Jack Napier, futuro Coringa.

No final, o Coringa não muda, mas segue sendo tão malicioso como era no início da história. Uma das adolescentes (MEG, menina, 12 anos) disse ter escolhido esse personagem "porque ele não está nem aí para nada, é considerado louco, mas não faz diferença, ele quer mais é que todo mundo se dane".

Sánchez Casarrubios (2012) destaca que o Coringa é um vilão carismático e representante do mal mais puro, com traços que lhe convertem em um tipo verdadeiramente temível, como bem disse um adolescente (DA, menino, 12 anos), que “ele é muito esperto, engraçado e dá medo...". Parte de um mito, e o renova com temas atuais. "A caracterização deste vilão é obviamente psicótica, ainda mais, que tem uma obsessão insana com Batman, seu arqui-inimigo” (SÁNCHEZ CASARRUBIOS, 2012, p. 200).

O interessante em sua conduta é a forma como faz as coisas, e não se precisa de mais nada para desfrutar desse personagem. Isso é atraente aos jovens, tanto que o personagem Coringa foi o mais escolhido na investigação. Os adolescentes justificam: "ele é engraçado e se diverte no que far" (GP, menino, 12 anos); "ele é um personagem de muita atitude" (VFA, menina, 12 anos).

${ }^{9}$ Pelo contexto, acreditamos que a menina quis dizer "objetivos". 
E nesse contexto, os adolescentes se identificam com os novos líderes políticos que fazem um uso tão intensivo dos meios de comunicação que minimizam alguns dos elementos básicos da representação política, o que favorece a alienação e o maniqueísmo dos conflitos e alternativas, impedindo a deliberação política, impondo a lógica do mercado acima da democracia. Como disse um adolescente (GRM, menino, 13 anos) para justificar, por exemplo, sua escolha pelo personagem Thanos: "ele tem um plano mal mas do jeito dele, é bom para o universo; se parece até com o Michel Temer".

A liderança pessoal, essência verdadeira das instituições políticas, não surge de uma identificação subjetiva com um líder, mas sim da própria relação representativa. A sobrevivência da política se baseia teoricamente nesta representação, que compõe uma vontade comum e uma autoridade legítima, como mediação entre a sociedade e o Estado.

Segundo Chatman (1990), “[...] os personagens esféricos possuem grande variedade de traços, alguns deles contrapostos ou contraditórios; sua conduta é imprevisível, são capazes de mudar, de nos surpreender [...]” (p. 141). Talvez por esse motivo os vilões sejam tão bem aceitos no universo adolescente, pois os surpreendem com suas ações, movimentando todo o seu contexto, não medindo esforços (mesmo que maléficos) para alcançar seus objetivos. Essa é uma característica que também pode ser esperada de um líder: ser aquele que age, que coordena tudo, que se dedica integralmente por uma causa, que traça planos e que conduz seu grupo ao sucesso. Mesmo sendo considerada uma imagem de liderança idealizada, pois atribui ao outro um poder que ele não tem (mas que aparenta ter, ou que o adolescente gostaria que tivesse), ela possibilita a construção de um vínculo entre liderado e líder, conecta o jovem com algo maior, algo que o transcende e traz sentido a sua existência. Líderes religiosos, líderes no mundo do trabalho, no bairro em que moram, ou os líderes dos grupos nas escolas, seja onde for, despertam também esse sentimento de pertencimento a algo e de conexão com algo maior.

\section{Líderes e anti-heróis}

Passamos neste ponto a explicar sobre as concepções de vilão/anti-herói, apesar de constatarmos poucos estudos que elucidem esse panorama. Sánchez Casarrubios (2012) afirma que há três grupos de vilões na atualidade, sendo que o primeiro grupo trata dos psicopatas, aqueles que têm a necessidade de cometer atrocidades devido aos seus delírios ou ânsias. É por isso que os anti-heróis dessa categoria, protagonistas de suas histórias, no cinema ou na TV, não necessitam de nada que os inspire a fazerem o que fazem, pois seguem suas próprias regras do jogo. É o caso dos personagens Thanos, da trilogia “Avengers" (2012-2019) e "Guardiões da Galáxia” (2018), e Ramsey Bolton, da série "Game of Thrones" (2011-2018).

Sobre Thanos, uma adolescente (GAL, menina, 13 anos) relata que "ele tem um objetivo e acaba conseguindo"; já outro sujeito (APR, menino, 12 anos) traz uma reflexão sobre o mesmo personagem,

\footnotetext{
${ }^{10}$ A pesquisa foi aplicada no final de 2018 , período das eleições presidenciais.
} 
dizendo que ele "possui um propósito para ser vilão, tem objetivos e expectativas de excelentes vilões". Sem dúvida, esses personagens têm uma meta, uma tarefa a cumprir, mas que não é dada a priori por ninguém que personifica a lei, pois eles encarnam a própria lei (SÁNCHEZ CASARRUBIOS, 2012), conforme justifica outro sujeito da pesquisa sobre o mesmo personagem: "Thanos: para ninguém passar necessidade, metade do mundo tem que sumir; é injusto, mas ele pensa que é certo" (SPP, menina, 12 anos).

O outro grupo de vilões corresponde a uma ameaça à vida dos protagonistas, e não precisa necessariamente ser uma pessoa, mas pode ser um fenômeno da natureza, um monstro ou um ser extraterrestre que, em todos os casos, configura o medo ao desconhecido. O personagem Voldemort poderia se enquadrar nessa categoria. Algumas falas dos adolescentes caracterizam bem essa colocação: "ele representa a maldade e a magia negra" (FCO, menina, 12 anos); "ele é muito poderoso..." (JVCAM, menino, 11 anos); "é uma lenda dos bruxos, poderoso e perigoso, mais inteligente e tem seus seguidores e os dementadores" (NRH, menino, 12 anos).

O terceiro grupo de vilões é político e bélico, tema que está na ordem do dia. E nesse ponto fazemos uma breve explicação sobre o conceito de anti-herói que temos tratado como sinônimo de vilão, mas há uma distinção: quando o vilão é o protagonista da história, ele está na posição de anti-herói, pois o vilão existe na medida em que é a réplica do herói. O anti-herói, como a própria palavra indica, representa os valores contrários aos do herói. Em muitas histórias o anti-herói assume o papel do protagonista, tornando-se assim o personagem principal da história.

Se, no caso do herói, o personagem se desenvolve a partir do conflito entre a justiça e a injustiça, o anti-herói é o que crê na injustiça e a torna sua própria forma de ver o mundo. No caso das lideranças políticas, estas muitas vezes podem ser encaradas como anti-heróis, pois se o papel dessas lideranças fosse o de atuar sempre no benefício positivo de seu povo, quando isso não ocorre assume-se um papel oposto ao bem comum, mesmo que não fique explícito. Se o vilão declara suas intenções e deixa evidente o seu lado na história, o anti-herói pode ser aquele que não assume essa posição, mas suas ações, quando analisadas, podem privilegiar somente seus interesses particulares ou de um grupo específico - como muitas vezes vê-se nas lideranças políticas.

Nessa concepção, podemos ainda inferir que o espectador tem muito mais coisas em comum com o anti-herói do que com o herói, pois ele faz coisas que todos gostariam de fazer um dia, principalmente os adolescentes que estão vivendo momentos em que a contravenção é mais atraente do que seguir regras sociais (LA TAILLE, 2008). Essas características do anti-herói são muito marcantes e aproximam-se muitas vezes do adolescente, que as admira: seu lado cínico e selvagem satisfaz o público jovem. É um personagem literário ou cinematográfico com o qual o leitor ou o espectador se identifica, passando a admirar as qualidades não heroicas e a debilidade que tradicionalmente não se atribui ao herói.

Costumam ser personagens alienados e isolados, vulneráveis às debilidades humanas, como a maioria dos adolescentes se sentem, mas que possuem um código ético próprio e, às vezes, uma integridade pessoal que os obriga a enfrentar a sociedade (KONIGSBERG, 2004), aspectos bastante 
atraentes aos adolescentes. Os vilões têm o poder de mostrar claramente aquilo que qualquer pessoa sente, mas que não deve priorizar. Representam o mal de cada pessoa e a mensagem moral de que esses valores errôneos só trazem sofrimento e fracasso.

Essas características se enquadram muito bem ao personagem Coringa, do filme "Batman - o Cavaleiro das Trevas" (2008). Um herói não é um herói, se não há um vilão para enfrentar. O antagonista é necessário para que o protagonista cumpra seus objetivos e supere os obstáculos que aparecem em seu caminho. Não pode existir o Bem sem o Mal, e o conflito básico entre os personagens geralmente está presente em toda a narrativa. Ambos se perseguem e sempre se enfrentam.

Assim, o anti-herói pode ser antissocial, muito inteligente, cruel, desagradável, obtuso ou simplesmente comum. Em outras palavras, um anti-herói é um protagonista que vive guiado por sua própria bússola moral, esforçando-se para definir e construir seus próprios valores, que são opostos àqueles reconhecidos pela sociedade em que vive. Como exemplo, temos o personagem Negan, da série “The Walking Dead” (2010-2019) e Rumpelstiltiskin, da série “Once Upon a Time” (2011-2018). E também se percebe que esse tipo de personagem anti-herói se transforma ao longo do filme ou série, pois vai recebendo punições que o levam ao caminho da redenção. São personagens que tiveram um passado trágico que deu origem à sua personalidade perturbada. As teorias psicológicas explicam a construção de personagens vilões, pois eles possuem uma visão corrompida do mundo que advém de traumas ocorridos na infância, como por exemplo, Lex Luthor, inimigo natural de Superman (do filme "Liga da Justiça", 2016), ou como o personagem Darth Vader, de "Star Wars - a última esperança”" (1977).

Darth Vader, apesar de não ter aparecido entre os mais selecionados na pesquisa, tem uma história muito interessante: estava do lado do Bem. Foi criado dentro de um sólido código de ética - o mundo Jedi. Mas, num dado momento de sua existência, seus conflitos interiores o fizeram inclinar-se para "o lado negro da força", perdendo tudo o que justamente temia perder e convertendo-se em um vilão terrível, capaz de eliminar vidas inocentes por uma simples ordem. Um dos adolescentes (GVM, menino, 13 anos) relata em sua justificativa: "bistória envolvente, mesmo sendo vilão teve uma história por trás que justifica". Assim como uma das adolescentes disse sobre o mesmo personagem: "eu acho seu passado muito triste e cruel, ele é uma pessoa bem obscura, com vários mistérios" (LOS, menina, 11 anos).

Podemos nos perguntar quais são os elementos que movem os vilões? Em relação aos heróis, é fácil deduzir, pois estão sempre buscando missões de resgate, vingança, perseguição e resolução de mistérios. Já o vilão/anti-herói não apresenta tanta variedade de objetivos, mas como explica SánchezEscalonilla (2002), alguns heróis buscam quase os mesmos temas, como vingança, perseguição e mistérios. O que os diferencia é que eles são o outro lado da mesma moeda. Como por exemplo, o herói tem uma motivação altruísta, e o vilão/anti-herói é egoísta.

O vilão, que muitas vezes é bem construído no início da narrativa, geralmente se resume às suas características básicas, salvo em casos excepcionais, como o personagem Voldemort, que conta com uma história forte por trás de sua maldade, pois normalmente espera-se que, ao final, o vilão seja simplesmente 
malvado. Acompanhamos a fala de uma das adolescentes, afirmando que "na história, ele (Voldemort) quer ser o bruxo mais poderoso e ele tem muita determinação e não tem medo" (MEB, menina, 13 anos).

$\mathrm{O}$ vilão é atualmente a peça-chave de qualquer filme de ação/aventura. É a parte mais atraente e a que mais prende o espectador, por mais que se solidarize com o herói, porque nas narrativas atuais, o herói depende mais do espetáculo do entorno em que se encontra, do que propriamente de suas convicções interiores.

Há uma história antiga a respeito da palavra "vilão", que provém de "vila". Na Idade Média, os vilões eram os bons e honestos habitantes das vilas que ficavam nos arredores das terras ou feudos dos membros da nobreza. Para esses proprietários de terras, o vilão era um sujeito bruto, ignorante e vulgar, um conceito elitista que, com o passar do tempo, se estendeu à concepção moral de vilão. Por essa razão, a palavra passou a ser usada para sujeitos que se destacavam por sua maldade e vilania (JIMÉNEZ GASCÓN, 2010).

\section{Atualidade e Anti-heróis}

A situação política e econômica da atualidade é devastadora. Há corrupção e crise econômica em níveis inimagináveis, e a sociedade se queixa afirmando que a maior parte dos políticos, senão todos, somente visam os seus próprios interesses, sem se importarem com a cruel realidade social. No filme "Batman - o Cavaleiro das Trevas" (2008), a genialidade da trama consiste em escolher um herói dos Comic Books $s^{11}$ alheio ao nosso mundo, já que a cidade de Gotham City não existe, convertido em um personagem totalmente verossímil, mas mantendo a ficção do universo de Batman. No filme, há também uma crise econômica e política não muito diferente da realidade. É uma ficção que não se distancia muito da sociedade atual, sociedade na qual os cidadãos duvidam constantemente de seus líderes políticos.

Entra em pauta não somente a identificação com os personagens, mas certas doses de verossimilhança e de coerência interna, tanto no mundo que rodeia o herói, o vilão ${ }^{12}$ o líder político, como na causa que os motiva e os obstáculos que se apresentam a essa causa, que envolve sempre certa nobreza de princípios. É possível que um aspirante a líder indague sobre a natureza do Mal para entendêla, mas, em dado momento, deverá ser consciente do caminho correto e segui-lo.

No filme "Batman" (2008), o principal aspecto da história coloca o protagonista Bruce Wayne em uma busca pela compreensão do Mal, representada pelo personagem Coringa. O personagem, assim como poderia fazer um líder político, necessita conhecer o lado obscuro para, de certa forma, encontrar a maneira de enfrentar esse Mal. Apesar de, em certo ponto, duvidar sobre o que fazer - se seria certo ou não -, acaba seguindo o lado do Bem. No final, deve prevalecer a justiça, pois há uma regra básica no mundo dos heróis e super-heróis:

\footnotetext{
11 Comic Books é a nomenclatura usada nos Estados Unidos para descrever qualquer história em quadrinhos. Os "comic books", ou revistas em quadrinhos, começaram a circular por volta de 1934 e tratam de gêneros variados, como ação e romance.

${ }^{12}$ Estamos nos referindo claro, ao Coringa, que foi o personagem mais selecionado pelos adolescentes.
} 
[...] existe uma fronteira que não se pode ultrapassar, e uma figura que pareça predominantemente malvada ou dedicada a fazer o mal, por mais atrativa que seja, não pode considerar-se um herói já que a palavra sempre deve denotar uma pessoa que admiramos por qualidades heroicas ou admiráveis, e que atua como algum tipo de ideal para todos (KONIGSBERG, 2004, p. 255).

É a partir da década de 1970 que surgem novas formas de entender o herói e, por consequência, o anti-herói, que antes se encontrava na categoria de mito. Graças aos estudos de Campbell (1989), ousaram desconstruir o processo mítico de forja do herói. No filme "Star Wars - a última esperança", de George Lucas (1977), há um exemplo de aplicação dos postulados desse autor. O protagonista passa a caminhar por uma rede de descobrimentos sobre si mesmo que determinaram sua condição heroica: o herói se faz a si mesmo.

A base psicológica entra então em pauta para moldar o ânimo dos personagens heroicos, algo que se apresentava de uma forma muito mais superficial em décadas anteriores. Ao ser mais consciente da superação pessoal, a trajetória do herói com seus conflitos, dúvidas e incertezas, inseguranças internas acabam se resolvendo e o percurso do personagem é de superação.

É importante destacar, em relação às figuras do vilão e do líder político, o fato de que no mundo contemporâneo foram redesenhadas suas naturezas, pois suas facetas obscuras e débeis assumiram certo protagonismo e servem de ponte para a autoexploração e o desfrute posterior das habilidades que foram conquistando. Todos os vilões e líderes nos mostram os defeitos do mundo em que vivemos, são o que são porque são capazes de se sobrepor aos obstáculos que lhes apresentam. Sendo uns mais transcendentais que outros, protagonizam os cenários com os quais se obtém uma visão distinta da realidade.

O filme "Batman - o Cavaleiro das Trevas" (2008) apresenta um final trágico, que une os aspectos discutidos neste estudo: a projeção simbólica e o engajamento cívico. No final trágico da história, o protagonismo deve sacrificar seu bom nome em favor de uma causa: que o povo não perca a fé na democracia e em seus políticos, ainda que tenham presenciado como o personagem Harvey Dent, que prometia uma carreira política comprometida e limpa, acaba se corrompendo, influenciado pelo Coringa, e, sobretudo, pela trágica morte de sua noiva. Batman obedece, assim, a sua integridade moral, impedindo os crimes do Coringa e do político Dent, para que a democracia não se desmorone. Seu sacrifício não é com a sua vida, mas com o seu nome e com a imagem política que os demais têm dele, ou seja, o símbolo que havia construído de si mesmo.

\section{Considerações finais}

Ao final da análise dos dados obtidos nesta pesquisa, foi possível compreender como os adolescentes concebem as lideranças políticas, por meio dos vilões e anti-heróis da TV e do cinema. Nos dados apontados, o Coringa despontou em evidência como principal vilão citado pelos adolescentes, sendo ele tomado para boa parte das reflexões geradas. 
Retomando o objetivo principal desta investigação sobre as percepções dos adolescentes em relação aos líderes políticos espelhados nos personagens fictícios, consideramos que este foi alcançado, pois estudos que possibilitem a compreensão de como os jovens têm as suas primeiras motivações para construírem a cidadania, como internalizam valores a partir de modelos significativos e como projetam a sua participação social é uma boa perspectiva para o campo educacional. Entendendo que a educação busca a realização do ser, vislumbra-se que esse propósito se dê em uma sociedade que favoreça a liberdade e a espontaneidade, e para que isso ocorra, é necessária a compreensão de como os adolescentes constroem suas identidades, e assim adequem as necessidades internas às possibilidades de sua realização.

É, portanto, uma formação cívica, pois se refere à orientação que se deve dar e receber para atuar como cidadãos livres e responsáveis, capazes de viver em uma democracia e promover os valores que ela fundamenta. Porém, ainda que possamos intuir o final de uma história, a surpresa é sempre indispensável. O espectador quer que os roteiros joguem com suas emoções, e, sobretudo, que lhe ofereça algo tangível, que seja suficientemente sólido para não cair na incredibilidade. Por que o personagem do Coringa é tão impactante? Por que foi o número um nas escolhas dos jovens? Como concluímos a pergunta desta pesquisa? A resposta, em parte, é a relação entre a realidade social e a ficção. Em Gotham City - cidade fictícia das histórias do Batman -, há uma onda de crimes e de corrupção, e Bruce Wayne/ Batman decide atuar como nunca havia feito antes.

Concluindo, os resultados deste trabalho chamam a atenção sobre a cidadania como aspecto tão importante para as pessoas que vivem em sociedade quanto o trabalho e a família, mas para o adolescente é um indicador da necessidade de promover um desenvolvimento positivo. E quando se fala em cidadania, não se pode desvincular o caráter formativo educacional. Os jovens podem e devem agir como participantes e como agentes de mudança, promovendo ações de qualidade na comunidade e na sociedade em geral, especialmente nos dias atuais, com a presença de fatos conflitantes do cenário político nacional e internacional, o que levanta três pontos centrais como alertas:

a) desenvolver um trabalho coletivo com os alunos, em uma gestão democrática, para planejar e tomar decisões na comunidade escolar, mediante discussão e debates sobre problemas sociais;

b) valorizar o professor, desenvolvendo seu lugar, como alguém que deve planejar e desenhar técnicas didáticas na sala de aula, fomentando atividades de aprendizagem significativa e de atualização cívica;

c) e introduzir, de maneira sistemática, meios para que os jovens, em suas aulas e em suas escolas, discutam questões políticas para obterem maior participação e engajamento na comunidade em que estão inseridos, enfatizando a convivência de distintas liberdades, de princípios democráticos e de justiça social. 


\section{REFERÊNCIAS}

ARISTOTELES. Retórica. Madrid: Gredos, 1997.

AVENGERS: Endgame. Direção: Joe Russo; Anthony Russo. USA: Marvel Studios/Walt Disney Studios Motion Pictures, 2019. DVD (181 min.).

AVENGERS: Era de Ultron. Direção: Joss Whedom. USA: Marvel Studios / Walt Disney Studios, 2015. DVD (141 min.).

AVENGERS: Infinity War. Direção: Joe Russo; Anthony Russo. USA: Marvel Studios/Walt Disney Studios Motion Pictures, 2018. DVD (149 min.).

BATMAN. Direção: Tim Burton. USA: Warner Bros, 1989. DVD (126 min.).

BATMAN vs Superman: Dawn of Justice. Direção: Zack Snyder. USA: DC Entertainment / Warner Bros. Pictures, 2016. DVD (151 min.).

BLONDELL, Jean. Political Leadership. Towards a general analysis. London: Sage, 1987.

CAMPBELL, Joseph. O herói de mil faces. Rio de Janeiro: Cultrix/Pensamento, 1989.

CHATMAN, Seymour. Historia y discurso. Madrid: Taurus Humanidades, 1990.

ERIKSON, E. H. Identidade: juventude e crise. Rio de Janeiro: Guanabara, 1987.

FIELD, S. Cómo mejorar un guión. Madrid: Plot Ediciones, 2002.

GAME of Thrones. Criação: David Benioff; D. B. Weiss. USA: Warner Bros. Television Distribution, 2011-2018. Série de TV (50 / 80 min.).

GONZALEZ REQUENA, J. Clásico, maneirista, postclásico. Los modos del relato en el cine de Hollywood. Valladolid: Castilla Ediciones, 2007.

GUARDIÕES da Galáxia. Direção: James Gunn. USA: Marvel Studios / Walt Disney Studios Motion Pictures, 2014. DVD (122 min.).

HARRY Potter e a Câmara Secreta. Direção: Chris Columbus. USA/ Reino Unido: Warner Bros Pictures, 2002. DVD (161 min.).

HARRY Potter e a Ordem da Fênix. Direção: David Yates. USA/ Reino Unido: Warner Bros Pictures, 2007. DVD (138 min.).

HARRY Potter e a Pedra Filosofal. Direção: Chris Columbus. USA/ Reino Unido: Warner Bros Pictures, 2001. DVD (152 min.).

HARRY Potter e as Relíquias da Morte - parte 1. Direção: David Yates. USA/ Reino Unido: Warner Bros Pictures, 2010. DVD (146 min.).

HARRY Potter e as Relíquias da Morte - parte 2. Direção: David Yates. USA/ Reino Unido: Warner Bros Pictures, 2011. DVD (130 min.). 
HARRY Potter e o Cálice de Fogo. Direção: Mike Newell. USA/ Reino Unido: Warner Bros Pictures, 2005. DVD (157 min.).

HARRY Potter e o Enigma do Príncipe. Direção: David Yates. USA/ Reino Unido: Warner Bros Pictures, 2009. DVD (153 min.).

HARRY Potter e o Prisioneiro de Azkaban. Direção: Alfonso Cuarón. USA/ Reino Unido: Warner Bros Pictures, 2004. DVD (142 min.).

JIMÉNEZ GASCÓN, Z. La construcción del villano como personaje cinematográfico. Frame, 6, 2010, p. 285-311.

KOLHBERG, L. Psicologia del desarollo moral. Bilbao: Desclée de Brower, 1984.

KONIGSBERG, Ira. Diccionario técnico akal de cine. Madrid: Akal, 2004.

LA TAILLE, Yves de. Formação ética: do tédio ao respeito de si. Porto Alegre: ArtMed, 2008.

MCKEE, Robert. El guión: sustancia, estrutura, estilo y princípios de la escritura de guiones. Barcelona: Alianza Editorial, 2002.

MOLANO, María del Mar Marcos. Elementos estéticos del cine. Manual de dirección cinematográfica. Madrid: Fragua, 2009.

MESQUITA, Marcos R.; BONFIM, Juliano; PADILHA, Erise; SILVA, Ana C. Juventudes e participação: compreensão de política, valores e práticas especiais. Psicologia \& Sociedade, v. 28, n. 2, p. 288-297, 2016.

NOVARO, Marcos. Representación y liderazgo en las democracias contemporáneas. Rosario: Homo Sapiens, 2000.

ONCE upon a time. Criação: Adam Horowitz; Edward Kitsis. USA: Disney TV / ABC Studios, 20112018. Série de TV (43 min.).

PÉREZ RUFI, José P. El análisis actancial del personaje: uma visión crítica. Espéculo: revista de estúdios literários, n. 38, 2008.

PIAGET, Jean. O juízo moral na criança. São Paulo: Summus Editorial, 1994.

SÁNCHEZ CASARRUBIOS, M. Narración y sociedade: el villano en el cine contemporâneo (20002010). Revista Aequitas, 2, 2012, p. 36. Disponível em: http://revistaaequitas.wordpress.com/2012/08/08/numero-2-2012-2/. Acesso em: 20 jul. 2020.

SÁNCHEZ-ESCALONILLA, Antonio. Guión de aventuras y forja del héroe. Barcelona: Ariel, 2002.

STAR Wars - Uma Nova Esperança. Criação: George Lucas. USA: 20th Century Fox, 1977. DVD (121 min.).

THE AVENGERS. Direção: Joss Whedom. USA: Marvel Studios / Walt Disney Studios, 2012. DVD (143 min.).

THE DARK Knight. Direção: Christopher Nolan. USA: DC Comics / Warner Bros. Pictures, 2008. DVD (152 min.). 
THE WALKING Dead. Criação: Frank Darabond; Robert Kirkman. USA: AMC Studios, 2010-2019. Série de TV (60 min.).

X-MEN Apocalypse. Direção: Bryan Singer. USA: Marvel Entertainment / 20th Century Fox, 2016. DVD (144 min.).

ZUKIN, Cliff; KEETER, Scott; ANDOINA, Molly; JENKINS, Krista; DELLI CARPINI, Michael X. A new engagement? Political participation, civic life and the changing American citizen. New York: Oxford University Press, 2006. 